\title{
Perception of Universal Healthcare among College Students, Faculty, and Staff at the University of Evansville
}

\author{
Sarah Harness, Dane Turner, Anthony Chastain, Payal Patel-Dovlatabadi \\ School of Health Sciences, University of Evansville, Evansville, IN, USA \\ Email:sh287@evansviile.edu,dt108@evansville.edu, ac378@evansville.edu,pp42@evansville.edu
}

How to cite this paper: Harness, S., Turner, D., Chastain, A. and Patel-Dovlatabadi, P. (2019) Perception of Universal Healthcare among College Students, Faculty, and Staff at the University of Evansville. Health, $11,308-321$.

https://doi.org/10.4236/health.2019.113027

Received: February 1, 2019

Accepted: March 10, 2019

Published: March 13, 2019

Copyright ( 2019 by author(s) and Scientific Research Publishing Inc. This work is licensed under the Creative Commons Attribution International License (CC BY 4.0).

http://creativecommons.org/licenses/by/4.0/

\begin{abstract}
The U.S. is a country founded on freedoms protected by our constitution. A debate rages currently about whether healthcare is a human right. We conducted a survey at the University of Evansville regarding perceptions of Universal Healthcare among students, faculty, and staff in the College of Education and Health Sciences. Over ninety percent of those who responded agreed that healthcare was a human right. This indicates a strong need for better policy discussion that includes the voice of the everyday person.
\end{abstract}

\section{Keywords}

Health Insurance, Human Right, Perceptions, Healthcare Policy, Universal Healthcare

\section{Introduction}

Universal Healthcare might not be a foreign concept in other countries, but since the idea was first introduced in the U.S. over 100 years ago, the topic has been highly controversial and has often reflected the politics currently at play. The World Health Organization stated in 2005 that everyone should have access to the health services they need without risk of financial ruin or impoverishment, and then reaffirmed this stance in 2012 [1]. As of 2015, 28.6 million Americans of all ages are without health insurance coverage [2]. While the majority of the country is familiar with Medicare, multiple studies have shown that the general population may be confused and biased against specific implementations of Universal Healthcare. This is illustrated in a study conducted by the Kaiser Family Foundation comparing Medicare-for-All and Single Payer [3]. While the opposition to Universal Healthcare has been examined and attempts 
have been made to explain why some people are opposed, a growing number of Americans have been found to support proposals to establish a system in the U.S.

Medicare-for-All is one of the better known proposed types of Universal Healthcare in the U.S. The proposed system would be maintained through taxes and would provide coverage to all residents. Through this system there would no longer be premiums, co-pays, or deductibles. Residents will have access to essential medical services and have the freedom to choose their providers [4].

Approximately $8.8 \%$ of the U.S. population does not have health insurance [5]. When examining developed countries, the U.S. is one of the very few that does not ensure access to Universal Healthcare for its citizens. Nations such as the United Kingdom and Canada have very well-known types of Universal Healthcare. The measure of success for such a system should be the health outcomes of the population. Such examples include infant mortality, maternal mortality, and cancer survival rates among other outcomes. Further, public perception of Universal Healthcare varies with economic fluctuations. This indicates a firm need for informed policy development. Citizens that are uninformed may hinder their own health outcomes if they do not understand the options that are available.

While the perceptions and attitudes of the general adult population towards Universal Healthcare have been studied and documented, there seems to be a gap in how college students view the movement. The Kaiser Family Foundation regularly polls those in the U.S. to find a baseline support/not support level on various Universal Healthcare proposals, and these polls are reported regularly. Despite this, our searches could only find two studies of note that focused specifically on college students. The first, conducted in 2010 by the University of Toledo College of Medicine, while expansive in studying 12 different undergraduate institutions, only focused on the broad subject of students and their insurance coverage. The issue of Universal Healthcare was largely a second thought, and was not the primary intention of the study [6]. The only study found relating to student views, opinions, or perceptions regarding Universal Healthcare was conducted at the Albert Einstein College of Medicine, and focused on medical students, which only form a percentage of the future healthcare providers in U.S. schools today. However, this study was conducted in 2009, long before Universal Healthcare began gaining traction with the general public [7]. Some additional studies regarding medical student perceptions and opinions regarding Universal Healthcare were identified as well, but because they were conducted in 2002 or earlier, they were not focused on. Identifying perceptions of the younger generation is essential as this is the next cohort that will be entering the workforce and many are covered by their parents' insurance so they may not be aware of the intricate nature of Universal Healthcare.

Given that the perceptions and attitudes of the younger population on Universal Healthcare have not been well-researched, we decided to examine this at a 
higher education institute. The University of Evansville College of Education and Health Sciences, located in Evansville, IN, offers multiple areas of study in health sciences, including Public Health, Exercise Science, Nursing, and Physical Therapy. With over 800 students, including those in undergraduate and graduate programs and just under 60 faculty and staff, the College offers a unique viewpoint to study the perceptions and opinions regarding Universal Healthcare in the U.S. We chose to focus solely on health-related areas of study as these are the students that would have had exposure to Universal Healthcare in a classroom setting and are future health care professionals. Further, faculty and staff perceptions would provide a good comparative measure within this study. Given that the literature is very limited in this area, the present study was conducted in hopes of filling the gap regarding perceptions of Universal Healthcare.

\section{Methodology}

The current study was a cross-sectional study involving primary data collection. The data was collected through an online survey provider, SelectSurvey.net. The survey, created in October 2018, was sent to 895 participants, 838 students and 57 faculty and staff. The number of participants was equivalent to the number of students enrolled in the College of Education and Health Sciences. Of the 895 participants surveyed, 292 completed the survey. The subjects were identified as students, faculty, and staff in the College of Education and Health Sciences at the University of Evansville. After distinguishing their role at UE, the survey directed the respondents to questions tailored to their identification. These questions were formatted to determine their respective disciplines within the College, and then the survey asked questions relating to healthcare and insurance. Questions regarding familiarity and support of a Universal Healthcare system, as well as questions about the current state of the U.S. healthcare system were included. These questions allowed us to evaluate and determine the general level of support for Universal Healthcare with students, faculty, and staff in the College of Education and Health Sciences.

Tables 1-4 show how the variables used in the study were coded. Most variables were classified as categorical while a few were classified as ordinal such as age, year of study, level of income, and support for Universal Healthcare. The

Table 1. Student demographics.

\begin{tabular}{|c|c|c|}
\hline Variable & Level of Measurement & Coding/Description \\
\hline \multirow{7}{*}{ Age } & \multirow{7}{*}{ Ordinal } & $1=18-24$ \\
\hline & & $2=25-34$ \\
\hline & & $3=35-44$ \\
\hline & & $4=45-54$ \\
\hline & & $5=55-64$ \\
\hline & & $6=65-74$ \\
\hline & & $7=75+$ \\
\hline Gender & Categorical & $\begin{array}{c}1=\text { Male } \\
2=\text { Female }\end{array}$ \\
\hline
\end{tabular}




\section{Continued}

\begin{tabular}{|c|c|c|}
\hline Race/Ethnicity & Categorical & $\begin{array}{c}1=\text { White } / \text { Caucasian } \\
2=\text { African American } \\
3=\text { Asian } \\
4=\text { Latino } \\
5=\text { Native } / \text { Indigenous } \\
6=\text { Other }\end{array}$ \\
\hline Status at the University & Categorical & $\begin{array}{c}1=\text { Student } \\
2=\text { Faculty } \\
3=\text { Staff }\end{array}$ \\
\hline Year of Study & Ordinal & $\begin{array}{c}1=\text { Freshman } \\
2=\text { Sophomore } \\
3=\text { Junior } \\
4=\text { Senior } \\
5=\text { Graduate }\end{array}$ \\
\hline Discipline of Study & Categorical & $\begin{array}{c}1=\text { Exercise Science } \\
2=\text { Public Health } \\
3=\text { Athletic Training } \\
4=\text { Health Service Administration } \\
5=\text { Nursing } \\
6=\text { Physical Therapy } \\
7=\text { Physical Therapy Assistant } \\
8=\text { Physician Assistant Science } \\
9=\text { Education } \\
10=\text { Clinical Laboratory Science } \\
11=\text { Other }\end{array}$ \\
\hline
\end{tabular}

Table 2. Faculty and staff demographics.

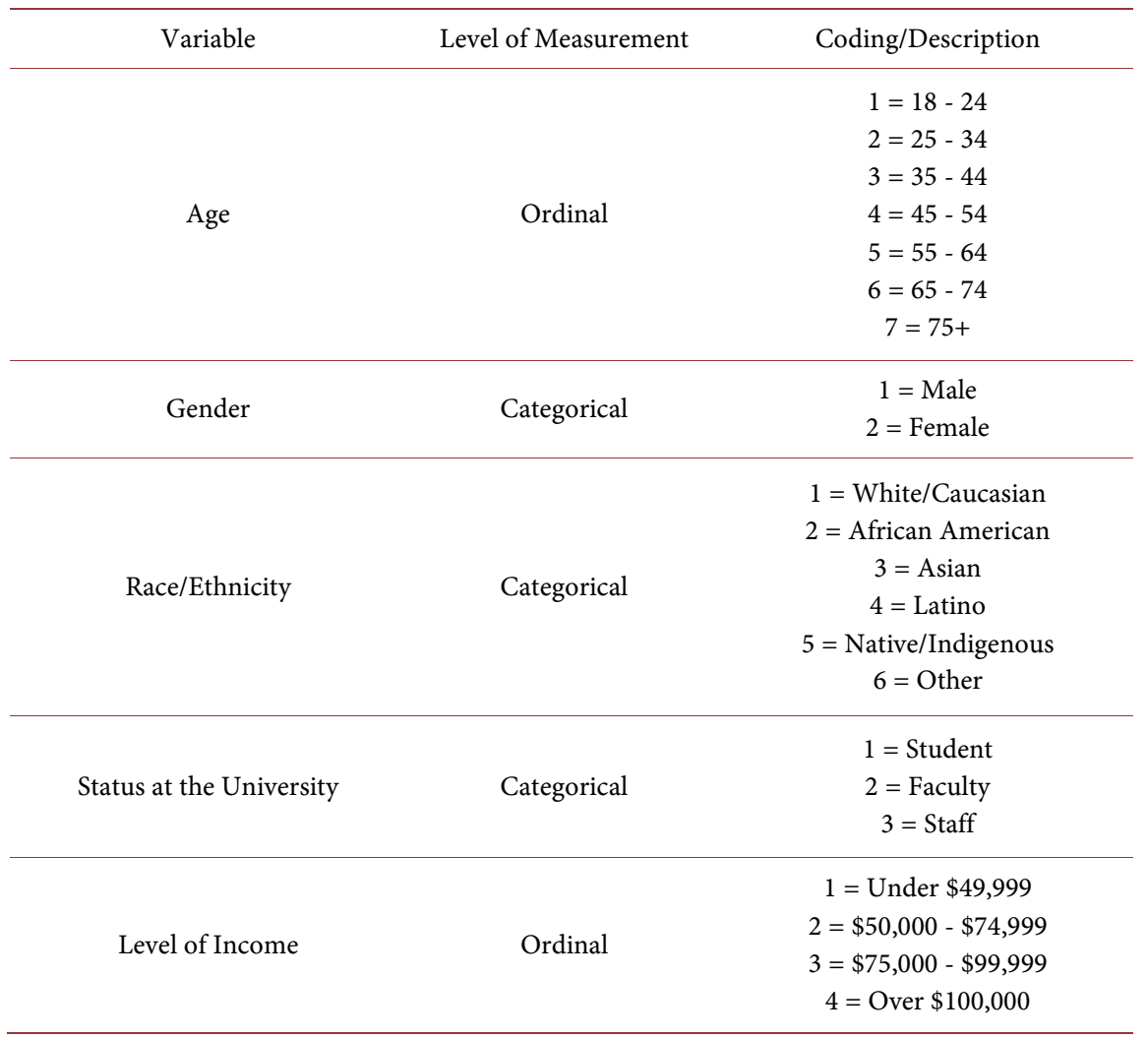


Table 3. Student perceptions of Universal Healthcare.

\begin{tabular}{ccc}
\hline Variable & Level of Measurement & Coding/Description \\
\hline Currently Have Health Insurance & Categorical & $1=$ Yes \\
$2=$ No
\end{tabular}

Table 4. Faculty/staff perceptions of Universal Healthcare.

\begin{tabular}{|c|c|c|}
\hline Variable & Level of Measurement & Coding/Description \\
\hline Currently Have Health Insurance & Categorical & $\begin{array}{l}1=\text { Yes } \\
2=\text { No }\end{array}$ \\
\hline Type of Health Insurance & Categorical & $\begin{array}{c}1=\text { Through Employer } \\
2=\text { Spouse's or Parent's Policy } \\
3=\text { Medicaid } \\
4=\text { Medicare } \\
5=\text { Other }\end{array}$ \\
\hline $\begin{array}{l}\text { Satisfaction with Current } \\
\text { Out-of-Pocket Expenses }\end{array}$ & Categorical & $\begin{array}{c}1=\text { Satisfied } \\
2=\text { Not Satisfied }\end{array}$ \\
\hline $\begin{array}{c}\text { Familiarity with Universal } \\
\text { Healthcare System }\end{array}$ & Categorical & $\begin{array}{c}1=\text { Familiar } \\
2=\text { Not Familiar }\end{array}$ \\
\hline Support for Universal Healthcare System & Ordinal & $\begin{array}{c}1=\text { Strongly Support } \\
\begin{array}{c}2=\text { Support } \\
3=\text { Neutral } \\
4=\text { Oppose } \\
5=\text { Strong Oppose }\end{array}\end{array}$ \\
\hline
\end{tabular}




\section{Continued}

\begin{tabular}{|c|c|c|}
\hline $\begin{array}{l}\text { Universal Healthcare Discussed } \\
\text { in Classroom }\end{array}$ & Categorical & $\begin{array}{l}1=\text { Yes } \\
2=\text { No }\end{array}$ \\
\hline Healthcare Is a Human Right & Categorical & $\begin{array}{l}1=\text { Yes } \\
2=\text { No }\end{array}$ \\
\hline $\begin{array}{l}\text { Government Obligation to } \\
\text { Protect Healthcare }\end{array}$ & Categorical & $\begin{array}{c}1=\text { Yes } \\
2=\text { No } \\
3=\mathrm{I} \text { Do Not Know }\end{array}$ \\
\hline $\begin{array}{c}\text { Changes Need to Be Made to Current } \\
\text { Healthcare System }\end{array}$ & Categorical & $\begin{array}{l}1=\text { Yes } \\
2=\text { No }\end{array}$ \\
\hline $\begin{array}{l}\text { Insurance Required for Those Older than } \\
\qquad 26\end{array}$ & Categorical & $\begin{array}{l}1=\text { Yes } \\
2=\text { No }\end{array}$ \\
\hline $\begin{array}{l}\text { Financial Penalty for Those without Health } \\
\text { Insurance }\end{array}$ & Categorical & $\begin{array}{l}1=\text { Yes } \\
2=\text { No }\end{array}$ \\
\hline
\end{tabular}

level of income and satisfaction with out-of-pocket costs were only asked of participants who selected staff or faculty. Questions relating to year of study, discipline of study, and how their education has affected their perceptions of Universal Healthcare were only asked of those identified as students.

An initial survey was sent to students, faculty, and staff along with two follow-up reminders. Regarding response rates, the goal was a $25 \%$ response rate after the initial survey, a 33\% response rate after the second attempt, and a $45 \%$ response rate after the third attempt.

Institutional ethical committee clearance was obtained. A database was created in MS Excel and descriptive statistical analysis was performed.

\section{Results}

Descriptive analyses are presented in Table 5. According to these analyses, approximately $95 \%$ of the participants indicated that they currently have health insurance and the majority of them (83\%) have it through their spouse or parent's policy. This is not surprising since $90.7 \%$ of participants were identified as students and $83.7 \%$ between the ages of $18-24$ years, meaning they are still qualified to be on their parent's insurance policy. The findings also show that there is an equal amount of familiarity regarding Universal Healthcare, 51.2\% are familiar and $48.8 \%$ are not familiar. The majority (40.5\%) of the participants have a neutral support for Universal Healthcare. The remaining participants are leaning more towards supporting (31\%) and strongly supporting (14.4\%) Universal Healthcare.

Regarding demographics, gender was drastically skewed, with nearly $84 \%$ of responses identifying as female. $91 \%$ of participants indicated that they came from a white/Caucasian background, with 2\% responding African American, $4 \%$ Asian, $1 \%$ Latino, and $1 \%$ identifying as other, with no respondents identifying as Native/Indigenous. The age of participants was predictably skewed towards the younger side of the scale, with $84 \%$ aged $18-24$. This is not surprising, seeing as just under $91 \%$ of participants were students, who typically fall in the 18 - 
Table 5. Frequency table.

\begin{tabular}{|c|c|c|c|}
\hline Variable & Variable & Frequency & Proportions (\%) \\
\hline \multirow{7}{*}{ Age } & $18-24$ years & 244 & 83.6 \\
\hline & 25 - 34 years & 13 & 4.5 \\
\hline & 35 - 44 years & 10 & 3.4 \\
\hline & 45 - 54 years & 14 & 4.8 \\
\hline & 55 - 64 years & 7 & 2.4 \\
\hline & $65-74$ years & 4 & 1.4 \\
\hline & $75+$ years & 0 & 0.0 \\
\hline \multirow{2}{*}{ Gender } & Male & 48 & 16.5 \\
\hline & Female & 243 & 83.5 \\
\hline \multirow{6}{*}{ Race } & White/Caucasian & 263 & 91.0 \\
\hline & African American & 6 & 2.0 \\
\hline & Asian & 12 & 4.2 \\
\hline & Latino & 4 & 1.4 \\
\hline & Native/Indigenous & 0 & 0.0 \\
\hline & Other & 4 & 1.4 \\
\hline \multirow{3}{*}{ Status at the University } & Student & 262 & 90.7 \\
\hline & Faculty & 19 & 6.6 \\
\hline & Staff & 8 & 2.8 \\
\hline \multirow{5}{*}{ Year of Study } & Freshman & 64 & 24.4 \\
\hline & Sophomore & 44 & 16.8 \\
\hline & Junior & 43 & 16.4 \\
\hline & Senior & 44 & 16.8 \\
\hline & Graduate & 67 & 25.6 \\
\hline \multirow{11}{*}{ Discipline of Study } & Exercise Science & 52 & 20.0 \\
\hline & Public Health & 15 & 5.8 \\
\hline & Athletic Training & 24 & 9.2 \\
\hline & Health Service Administration & 10 & 3.9 \\
\hline & Nursing & 46 & 17.7 \\
\hline & Physical Therapy & 45 & 17.3 \\
\hline & Physical Therapy Assistant & 5 & 1.9 \\
\hline & Physician Assistant Science & 16 & 6.2 \\
\hline & Education & 35 & 13.5 \\
\hline & Clinical Laboratory Science & 0 & 0.0 \\
\hline & Other & 12 & 4.6 \\
\hline \multirow{3}{*}{$\begin{array}{l}\text { Currently Have Health } \\
\text { Insurance }\end{array}$} & Yes & 273 & 94.5 \\
\hline & No & 8 & 2.8 \\
\hline & I Do Not Know & 8 & 2.8 \\
\hline \multirow{5}{*}{ Type of Health Insurance } & Through Employer & 22 & 8.1 \\
\hline & Spouse or Parent's Policy & 224 & 82.7 \\
\hline & Medicaid & 13 & 4.8 \\
\hline & Medicare & 2 & 0.7 \\
\hline & Other & 10 & 3.7 \\
\hline \multirow{2}{*}{$\begin{array}{c}\text { Familiarity with Universal } \\
\text { Healthcare }\end{array}$} & Familiar & 147 & 51.2 \\
\hline & Not Familiar & 140 & 48.8 \\
\hline \multirow{5}{*}{$\begin{array}{l}\text { Support for Universal } \\
\text { Healthcare }\end{array}$} & Strongly Support & 41 & 14.4 \\
\hline & Support & 88 & 31.0 \\
\hline & Neutral & 115 & 40.5 \\
\hline & Oppose & 31 & 10.9 \\
\hline & Strongly Oppose & 9 & 3.2 \\
\hline \multirow{3}{*}{$\begin{array}{l}\text { Universal Healthcare } \\
\text { Discussed in Classroom }\end{array}$} & Yes & 86 & 31.4 \\
\hline & No & 154 & 56.2 \\
\hline & I Do Not Know & 34 & 12.4 \\
\hline
\end{tabular}




\section{Continued}

\begin{tabular}{|c|c|c|c|}
\hline Healthcare Is a Human & Yes & 255 & 91.1 \\
\hline Right & No & 25 & 8.9 \\
\hline \multirow{3}{*}{$\begin{array}{c}\text { Government Obligation to } \\
\text { Protect Healthcare }\end{array}$} & Yes & 205 & 80.7 \\
\hline & No & 15 & 5.9 \\
\hline & I Do Not Know & 34 & 13.4 \\
\hline \multirow{2}{*}{$\begin{array}{c}\text { Changes Need to Be Made } \\
\text { to Current Healthcare } \\
\text { System }\end{array}$} & Yes & 267 & 96.0 \\
\hline & No & 11 & 4.0 \\
\hline \multirow{2}{*}{$\begin{array}{c}\text { Insurance Required for } \\
\text { Those Older than } 26\end{array}$} & Yes & 197 & 71.1 \\
\hline & No & 80 & 28.9 \\
\hline \multirow{2}{*}{$\begin{array}{l}\text { Financial Penalty for } \\
\text { Those without Health } \\
\text { Insurance }\end{array}$} & Yes & 74 & 27.0 \\
\hline & No & 200 & 73.0 \\
\hline \multirow{4}{*}{ Level of Income } & Under $\$ 49,999$ & 6 & 23.1 \\
\hline & $\$ 50,000-\$ 74,999$ & 10 & 38.5 \\
\hline & $\$ 75,000-\$ 99,999$ & 4 & 15.4 \\
\hline & Over $\$ 100,000$ & 6 & 23.1 \\
\hline Satisfaction with & Satisfied & 18 & 66.7 \\
\hline Out-of-Pocket Costs & Not Satisfied & 9 & 33.3 \\
\hline
\end{tabular}

24 age category. Regarding students, the breakdown of area of study was fairly equal, with the leading categories; exercise science, nursing, and physical therapy each making up around $20 \%$, education around $14 \%$, and the rest split up among the other areas of study. Regarding year of study, freshman and graduate students made up around $25 \%$ of responses each, with the other $50 \%$ split equally between sophomores, juniors, and seniors.

Students had the opportunity to discuss how their education has changed their perception of Universal Healthcare. Table 6 highlights 20 of the 165 responses received. Many students stated that their education has shown them that Universal Healthcare works in other countries. They also discussed the struggles with the current U.S. healthcare system.

The students were also given an opportunity to provide any additional comments. A sample of the responses is shown in Table 7. A total of 44 responses were provided.

Similarly, at the end of the survey, the faculty and staff had the opportunity to provide any additional comments. Table 8 provides a sample of the 8 comments submitted by the faculty and staff.

\section{Discussion}

Our survey was based on the hypothesis that students, faculty, and staff in the College of Education and Health Sciences would support Universal Healthcare. Based on our results, we can conclude that our primary hypothesis is supported, with $85.9 \%$ of the participants indicating that they were either neutral, supportive, or strongly supportive of a Universal Healthcare system. This indicates that at the policy level, leaders should start discussing how to go about creating such a system. At the local community level, grassroots initiatives should create focus 
Table 6. Student education perception.

\section{How Has Your Education Changed Your Perception on Universal Healthcare?}

It has made me more aware of those that struggle with health care rights and the children especially in school systems who do not have access to healthcare.

My education allows me to see the effects of why Universal Healthcare should be implemented. People shouldn't have to pay for their basic human right to the proper care and medical attention they need and require.

It has opened my eyes to different health care systems across the globe that seem to be more successful and accessible to all people than the U.S system.

My education helped me understand that all people, even those who are young and healthy, need to have health insurance because it spreads the burden of cost among the entire population rather than just those who are very sick.

I have learned more about how health insurance works in my first Health Service Administration class and it has made me realize healthcare is not accessible to everyone.

Helped me realize that implementing it requires compromises.

My education has made me realize the broken health care system and how much money healthcare consumes on our national GDP. A universal health care system might be expensive, but some of the best countries for healthcare follow a Universal Healthcare system, such as Japan.

It changed it from being against universal health care to being neutral and being able to understand the benefits.

I believe that everyone should have insurance, regardless of their education. My education has encouraged me to find a career that offers a health insurance plan.

It's made me realize that everyone deserves the right to a healthy life, so they should have access to healthcare without the fear of financial burdens (or other factors) affecting their lifestyle.

My education has opened my mind up to all the possibilities of health insurance. I am more educated and exposed to all sides of the health care system in addition to other policies from other countries. I am able to see the pros and cons to each system.

Universal Healthcare sounds great but I believe that it has its own slew of issues that accompany it.

I believe that everyone has the right to free healthcare and it's the government responsibility to protect that right. My education taught me that healthcare isn't cheap and some people find it cheaper to pay the fine then to get insurance.

I worked in a Universal Healthcare system in another country for class and have seen the negatives to it. I used to think it was great but they way I saw it ran, was not great. Was more scary.

It has definitely highlighted the difficulty and the challenges that will be faced to be able to implement Universal Healthcare in the United States. It has also illustrated both the benefits and drawbacks of a Universal Healthcare system. I think my perception has not changed a lot but I have become more informed.

My education has made me think more about how we need to make changes. We need to be fairer to all levels of income. All people should have access to healthcare.

My education in the DPT program has taught me that all patients require individualized care. Universal Healthcare has the potential to not allow individualized care. Insurance companies currently have too much control over patient care and I fear that if Universal Healthcare exists patients will not get the individualized care they deserve due to stricter regulations and guidelines.

In studying abroad, I have had the opportunity to speak with people all over the globe about the health care system in their home country. Before this, I never would have known that people of India have a Universal Health care system or even what a universal health care system is. Finland and other Nordic countries also have a universal health care system because of their heavier taxes. This is more along the lines of how it should be in the US.

Our healthcare system is lacking compared to other countries. We spend way more money than other countries but have about the same results. We wait till the problem is bad then try to fix it rather than trying to prevent it in the first place. 


\section{Continued}

Simply learning in Global Health Issues that the United States is one of the only developed countries that don't consider health a citizen's right fully changed my perspective. It doesn't make sense to me why it wouldn't be if we have the rights to speech, religion, owning property, etc... It should be a necessary component of each citizen's life and the government should control that and help its citizens out.

Table 7. Student open-ended responses.

\section{Additional Comments?}

I think the U.S. system needs a major transformation because it doesn't treat health care as a universal right.

Extraordinary wait times, triage of patients based on tax paying abilities, distance from hospitals, lack of preventative medicine, lack of follow up care, lack of electronic medical records, lack of patient centered care are some of the major flaws I have seen firsthand in a Universal Healthcare system.

I do feel that the United States healthcare system needs modification. Many Americans are not educated well enough on what all factors into the system.

Everyone needs healthcare. The difficulty is how to obtain in. I think insurance companies are one of the problems with healthcare. They have added to the cost of healthcare and they seem to care about their bottom line not what is best for the patient. There are so many factors that go into this. It starts with people taking charge of their own health.

I don't think Universal Healthcare is a good idea. Just because other countries do it doesn't mean America should.

Table 8. Faculty/staff open-ended responses.

\section{Additional Comments?}

The best thing that could happen to America would be a universal health care system.

I think greed on the part of insurers/pharmaceutical companies/hospital systems has led to unethical practices, which have skyrocketed costs. It is not ethical, nor should it be standard practice, for any entity to charge exorbitant costs for life-saving treatments and interventions. True medicine is healing and gives without thought of self-profit.

Universal health care sounds like a wonderful thing until you see what can happen with long waits for services, rationing services, limiting service areas to wider regional areas or using ageism as reasons to withhold services. Spend time in England and one will see that universal health care is not perfect either.

I think for starters that Medicare age requirements could be lowered from 65 to 55 .

groups to engage local politicians and the community. With many participants supporting Universal Healthcare, discussion on the topic needs to be discussed more in the classroom.

Furthermore, a majority of the participants believed changes need to be made to our current healthcare system. From the open-ended questions, some of the remarks included, "I believe that everyone has the right to free healthcare and it's the government responsibility to protect that right" and "My education has made me think more about how we need to make changes. We need to be fairer to all levels of income. All people should have access to healthcare." Much of our current political climate is focused on eliminating or protecting the Affordable 
Care Act when in reality there should be a focus on ways it can be improved and be more efficient. Current leaders should examine how other countries with a Universal Healthcare system have found success, considering the limitations and drawbacks of such a system. The U.S.'s position is unique and what has been implemented in other countries might not necessarily be ideal for the U.S. population. Therefore, a tailored system is needed for the U.S. that draws inspiration from other countries with Universal Healthcare.

The findings also show that there is an equal amount of familiarity regarding Universal Healthcare, $51.2 \%$ are familiar and $48.8 \%$ are not familiar, which is not unexpected because of the exposure the media has provided. This indicates that people need to become more informed and also indicates an area in which students may need additional education at the University of Evansville. The media is not the appropriate platform for providing this information. Leaders across the spectrum need to formulate a plan to educate people on what exactly Universal Healthcare can be. Biased news sources will not allow for such information. One particular aspect of the data shows that the single biggest category for support was actually the neutral option. Coupling this with the familiarity, human right, government protection, and a need for change responses give a clear picture of confusion. The familiarity response demonstrates the most pertinent need to address Universal Healthcare with policy through community action.

It is interesting to see that the majority of the participants said that those older than 26 should be required to have health insurance yet they said there should not be a financial penalty for those without health insurance. This is surprising since it is typically those who are 26 that do not have health insurance, as this is the age where children can no longer be included on their parent's health insurance plan. However, when compared with the question that asked if those without insurance should face a financial penalty, a large majority said that there should not be a financial penalty. This indicates that while participants felt it was necessary to mandate insurance coverage for certain people, they did not agree that financial penalties, which are highly debated and used under the Affordable Care Act, should be used. A majority of the respondents strongly support the basic tenets of Universal Healthcare, including that it is a human right and the government should protect this right. They all greatly support a change to the current system, yet do not want any consequences if they chose not to have health insurance. This brings it back to the need for a change in the current U.S. healthcare system.

Many of the open-ended responses for students, faculty, and staff indicate common misconceptions about Universal Healthcare. For example, long wait times are indicated by some as a reason against such a system. In many of the responses people indicate support, but have concerns about how to implement Universal Healthcare. Some students acknowledge how their education has impacted their perceptions of healthcare. Some respondents indicated a change in opinion towards systems of Universal Healthcare when traveling to other coun- 
tries with these systems.

When compared to the two studies we selected that were conducted by the Albert Einstein College of Medicine and the University of Toledo College of Medicine, our study chose not to focus on medical school students. This allowed us to collect information from a full spectrum of future health providers, including nurses, physical therapists, physician assistants, and public health professionals, among others. Observing the opinions of these participants and the faculty and staff that they interact with allows our study to paint a broader picture of the true opinions and perceptions held by those in healthcare professions. However, this also caused the main limitation in our study, in that we did not include any medical school students because the University of Evansville does not house a College of Medicine. Additionally, when compared to these other studies, ours is the only one to take place after the implementation of the Patient Protection and Affordable Care Act, with Toledo's study taking place during the actual period leading up to the passage of the law. However, when comparing the actual data, all studies supported the idea that it is the responsibility of the federal government to ensure every citizen has health insurance. Most importantly, each study shows that the majority of future healthcare providers surveyed believe the U.S. needs to implement a Universal Healthcare system.

The limitations of the study are largely a result of the group from which participants were chosen. Since our study only focused on students, faculty, and staff within the College of Education and Health Sciences at the University of Evansville, our findings may not hold true when compared to similar studies that could be conducted at other universities. A possible way to expand on the population and thus the results would be to include similar bodies of students at other local universities. The Indiana University School of Medicine - Evansville and the College of Nursing and Health Professions at the University of Southern Indiana both would have added participants from areas of study not represented within our respondents. Additionally, our results are limited because we only asked about participant's perception of Universal Healthcare as a concept, instead of asking about specific Universal Healthcare proposals including Medicare for All, expanding Medicare and Medicaid or the creation of a new national health system which has shown to result in varying levels of support for specific concepts [8].

Despite the limitations of the study, it does provide a strong basis for future studies conducted at similar universities across the U.S. Improvements could include questions regarding various Universal Healthcare proposals. Adding such questions would allow for the study of a participant's feelings about specific wording as opposed to the concept as a whole. Conducting the study at other universities would allow for broader findings and a greater representation of the perceptions of Universal Healthcare by future healthcare providers in the U.S., as opposed to limiting findings to students, faculty, and staff from the University of Evansville. 


\section{Conclusion}

Overall, the perceptions of Universal Healthcare lean towards supporting this concept. It has never been more pertinent than now to address healthcare reform. Surveying future healthcare professionals has allowed a better understanding of where to start the discussion of Universal Healthcare. As the U.S. population ages the healthcare system will only become more burdened. In turn, we will see a higher demand on Medicare. This inevitable fact will require significant changes to the healthcare system that only an open and honest discussion will provide. The sooner we address the issues with our current healthcare system, the more lives will be improved.

\section{Acknowledgements}

We would like to thank the Institute for Public Health at the University of Evansville for its support with the research and the publication of this article.

\section{Conflicts of Interest}

The authors declare no conflicts of interest regarding the publication of this paper.

\section{References}

[1] Campbell, J., Buchan, J., Cometto, G., David, B., Dussault, G., Fogstad, H., Fronteira, I., Lozano, R., Nyonator, F., Pablos-Mendez, A., Quain, E., Starrs, A. and Tangcharoensathien, V. (2013) Human Resources for Health and Universal Health Coverage: Fostering Equity and Effective Coverage.

http://www.who.int/bulletin/volumes/91/11/13-118729.pdf

[2] Center for Disease Control and Prevention (2016) Lack of Health Insurance Coverage and Type of Coverage. Early Release of Selected Estimates Based on Data from the National Interview Survey, 2015. https://www.cdc.gov/nchs/data/nhis/earlyrelease/earlyrelease201605_01.pdf

[3] Altman, D. (2016) Medicare-for-All vs. Single Payer: The Impact of Labels. https://www.kff.org/health-reform/perspective/medicare-for-all-vs-single-payer-the -impact-of-labels/?fbclid=IwAR0x3f4G5i3NQmlzlSLkbUWxa-FwGUQPPzDjXLXX dB2SoKOOxfc3vXRoEgI

[4] About Single Payer (n.d.) http://pnhp.org/what-is-single-payer/

[5] Berchick, E., Hood, E. and Barnett, J. (2018) Health Insurance Coverage in the United States: 2017.

https://www.census.gov/library/publications/2018/demo/p60-264.html

[6] Price, J., Khubchandani, J., Dake, J., Thompson, A., Schmalzried, H. and Adeyanju, M., et al. (2010) College Students' Perceptions and Experiences with Health Insurance. Journal of the National Medical Association, 102, 1222-1230. https://doi.org/10.1016/S0027-9684(15)30777-X

[7] Benson, A., Mendelsohn, N., Gervits M., Adeshuko, F., Garcia, C. and Smoller, S. (2009) Medical Student Views of Healthcare Reform in the United States, 2009. http://www.einstein.yu.edu/uploadedFiles/EJBM/27.1\%20Benson.PDF?n=4107

[8] Kirzinger, A., Muñana, C. and Brodie, M. (2018) KFF Health Tracking Poll-January 
2019: The Public on Next Steps for the ACA and Proposals to Expand Coverage. https://www.kff.org/health-reform/poll-finding/kff-health-tracking-poll-january-20 $\underline{19 /}$ 